\title{
A simple representation of surface active organic aerosol in cloud droplet formation
}

\author{
N. L. Prisle ${ }^{1,2}$, M. Dal Maso ${ }^{1}$, and H. Kokkola ${ }^{2}$ \\ ${ }^{1}$ University of Helsinki, Department of Physics, P.O. Box 48, 00014, University of Helsinki, Finland \\ ${ }^{2}$ Finnish Meteorological Institute, Kuopio Unit, P.O. Box 1627, 70211, Kuopio, Finland
}

Received: 17 September 2010 - Published in Atmos. Chem. Phys. Discuss.: 11 October 2010

Revised: 7 March 2011 - Accepted: 5 April 2011 - Published: 4 May 2011

\begin{abstract}
Atmospheric aerosols often contain surface active organics. Surface activity can affect cloud droplet formation through both surface partitioning and surface tension reduction in activating droplets. However, a comprehensive thermodynamic account for these effects in Köhler modeling is computationally demanding and requires knowledge of both droplet composition and component molecular properties, which is generally unavailable. Here, a simple representation of activation properties for surface active organics is introduced and compared against detailed model predictions and laboratory measurements of $\mathrm{CCN}$ activity for mixed surfactant-salt particles from the literature. This simple organic representation is seen to work well for aerosol organic-inorganic composition ranges typically found in the atmosphere, and agreement with both experiments and detailed model predictions increases with surfactant strength. The simple representation does not require resolution of the organic aerosol composition and relies solely on properties of the organic fraction that can be measured directly with available techniques. It can thus potentially be applied to complex and ambient surface active aerosols. It is not computationally demanding, and therefore has high potential for implementation to atmospheric models accounting for cloud microphysics.
\end{abstract}

\section{Introduction}

The indirect climate effect of atmospheric aerosol particles via cloud formation and properties still constitutes the single largest uncertainty in assessing the anthropogenic contribution to global climate change (IPCC, 2007). The cloud condensation nuclei $(\mathrm{CCN})$ properties of aerosol particles are

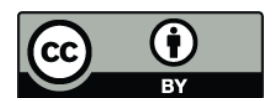

Correspondence to: N. L. Prisle (nonne.prisle@helsinki.fi) determined by both size and chemical composition. Presence of surface active molecules (surfactants) has been demonstrated in bulk samples of atmospheric cloud and fog waters (Facchini et al., 1999, 2000), as well as in aerosol samples (Yassaa et al., 2001; Mochida et al., 2003; Cheng et al., 2004) and aqueous extracts thereof (Oros and Simoneit, 2000; Mochida et al., 2002; Kiss et al., 2005; Dinar et al., 2006; Asa-Awuku et al., 2008) from marine, and rural and urban/polluted continental environments. A number of the identified surface active organic molecules have been observed in laboratory experiments to be $\mathrm{CCN}$ active at atmospheric conditions and surface activity can significantly affect the CCN properties of these compounds (Prisle et al., 2010, 2008). Comparison to detailed model predictions from thermodynamically consistent relations suggests that surface activity influences cloud droplet activation via both surface partitioning and surface tension effects. However, the combined effect on CCN activity of these mechanisms is not readily anticipated in each case (Prisle et al., 2010, 2008, and references therein).

To improve estimates of the aerosol indirect climate effects and predictions of future climate, a correct description of organic aerosol properties, such as surface activity, in atmospheric models accounting for cloud microphysics is therefore essential. In previous work, the surface partitioning equilibrium and surface tension of activating droplets were determined from numerical solutions to thermodynamic relations (Prisle et al., 2010, and references therein). Such calculations are however computationally too demanding for implementation into atmospheric models (Kokkola et al., 2006). Furthermore, the use of thermodynamically consistent relations requires knowledge of droplet composition, and composition-dependent properties, in terms of aqueous solution water activity and surface tension, that are generally not available for aerosol compositions such as those found in the atmosphere. Finally, the detailed model cannot be applied in its current form to aerosol systems with more than three

Published by Copernicus Publications on behalf of the European Geosciences Union. 
components (Prisle et al., 2010, 2008; Sorjamaa et al., 2004). Recent works by Topping (2010) and Raatikainen and Laaksonen (2010) address in particular the first point and present approximate analytical solutions to the partitioning equilibrium that do not require iterative procedures. Nevertheless, both solutions still require knowledge of particle compositions and component properties.

In this work, we adopt a different approach and introduce a simple representation for the activation properties for surface active organics, based on insights to the behavior of organic surfactants in cloud droplet activation gained from model predictions employing detailed thermodynamic relations. Köhler predictions using this simple representation are compared to laboratory measurements and detailed model calculations of $\mathrm{CCN}$ activity for mixed organic surfactantinorganic salt particles of atmospheric relevance from the literature.

\section{Theory and modeling}

\subsection{Köhler theory}

Cloud droplets form in the atmosphere when water vapor condenses on the surfaces of aerosol particles. As the aqueous phase forms, particle constituents may dissolve into solution droplets. The equilibrium growth and activation of such an aqueous solution droplet is described by the Köhler equation (Köhler, 1936), relating the equilibrium water vapor supersaturation $(S S)$ over a spherical droplet to its diameter $(d)$ :

$$
\frac{S S}{[100 \%]} \equiv \frac{p_{\mathrm{w}}}{p_{\mathrm{w}}^{0}}-1=a_{\mathrm{w}} \exp \left(\frac{4 v_{\mathrm{w}} \sigma}{R T d}\right)-1 .
$$

Here, $p_{\mathrm{w}}$ is the equilibrium partial pressure of water over the solution droplet, $p_{\mathrm{w}}^{0}$ is the saturation vapor pressure over a flat surface of pure water, $a_{\mathrm{w}}$ is the droplet solution water activity, $v_{\mathrm{w}}$ is the partial molar volume of water in solution, $\sigma$ is the droplet surface tension, $R$ is the universal gas constant, and $T$ is the temperature (in Kelvins).

The water activity describes the suppression by dissolved solutes of the equilibrium partial pressure of water over an aqueous solution, compared to the pure water saturation vapor pressure, according to the generalized Raoult's Law:

$p_{\mathrm{w}}=\gamma_{\mathrm{w}} x_{\mathrm{w}} p_{\mathrm{w}}^{0}=a_{\mathrm{w}} p_{\mathrm{w}}^{0}$.

Here, $x_{\mathrm{w}}$ is the water mole fraction in solution and $\gamma_{\mathrm{w}}$ is the corresponding mole-fraction based activity coefficient of water. The exponential term in Eq. (1) is equivalently called the Kelvin term and describes the enhancement of vapor pressure over a concave curved droplet surface, compared to a flat liquid surface, by the Kelvin effect. These two opposing effects on equilibrium water partial pressure define a maximum equilibrium supersaturation for growing droplet sizes, or a critical supersaturation $\left(S S_{\mathrm{c}}\right)$, with a corresponding critical droplet diameter $\left(d_{\mathrm{c}}\right)$, that must be surpassed for droplets to activate and grow into full-sized cloud drops.
The Kelvin term depends explicitly on droplet surface tension. Any reduction in surface tension by dissolved surfactants will decrease the vapor pressure enhancement at a given droplet size and corresponding surface curvature and therefore also decrease the critical supersaturation for the droplet.

\subsection{Surface partitioning}

Surfactants preferentially accumulate at the air-water interface of aqueous solutions. In Gibbs adsorption theory (Gibbs et al., 1928), this is described by the partitioning of surfactant molecules within a solution between an isotropic bulk phase (superscript B in the following), and an anisotropic surface phase (superscript $S$ ) with a steep surfactant radial density gradient, separated by an infinitely thin dividing surface. The relative distribution of surfactant solute between these distinct solution phases is referred to as the (bulk-)surface partitioning and depends on the intrinsic propensity of surfactant molecules for the surface, as well as the relative dimensions of the solution bulk and surface phases, described by the surface-area-to-bulk-volume ratio (Prisle et al., 2010, and references therein). For spherical droplets, this quantity is given by the diameter as:

$\frac{A}{V}=\frac{6}{d}$.

As surfactant molecules partition to the solution surface, their concentration in the bulk phase is simultaneously depleted. Solution droplets involved in cloud droplet formation typically have sub-micrometer diameters and thus $A / V \gg 1 \mu \mathrm{m}^{-1}$, whereas for a macroscopic solution $A / V \rightarrow 0 \mu \mathrm{m}^{-1}$ as $d \rightarrow \infty$. In small droplets, surface partitioning and the resulting bulk-phase depletion of surfactant molecules can significantly affect solution properties (Seidl and Hanel, 1983; Bianco and Marmur, 1992; Laaksonen, 1993). Droplet bulk-phase depletion will result in relatively larger water activity (a diminished water partial pressure suppression) and surface tension (a diminished solution surface tension reduction) from a given total (superscript $\mathrm{T}$ ) concentration of dissolved surfactant within the droplet phase. Surface partitioning may thus be anticipated to affect cloud droplet activation through both water activity and Kelvin effects.

Analogously to Prisle et al. (2010), surfactant strength is here quantified as the surface tension reduction from that of pure water, attained at a given surfactant bulk phase concentration $\left(c_{\mathrm{SFT}}^{\mathrm{B}}\right)$ in solution

Surfactant strength $=\Delta \sigma\left(c_{\mathrm{SFT}}^{\mathrm{B}}\right)=\sigma_{\mathrm{w}}-\sigma\left(c_{\mathrm{SFT}}^{\mathrm{B}}\right)$.

The strength of a surfactant is this way determined by both the nature of molecular interactions and the concentration gradient in the anisotropic surface, as given from an appropriate adsorption isotherm, for example the Langmuir-based Szyskowski equation (Szyskowski, 1908). In macroscopic 
solutions, a strong surfactant can yield a large reduction in surface tension, compared to pure water, at a given concentration by being strongly partitioned to the surface and/or displaying molecular interactions to enable efficient reduction in the solution surface tension. Inorganic salts can influence individual surfactant properties (Lin et al., 2005; Tuckermann, 2007; Vanhanen et al., 2008; Prisle et al., 2010) by enhancing surfactant activity in solution through both solute-solute non-ideal interactions and common ions decreasing the contribution from organic ions to the overall surfactant solubility product. Surfactant strength, as quantified in Eq. (4), is therefore affected by the mixing state of solutes within an aqueous solution. In microscopic activating droplets, the surface tension reduction attained from a given strong surfactant is not immediately evident. From simple Köhler theory, it is predicted that spherical dry particles with larger diameters $\left(D_{\mathrm{p}}\right)$ activate with critical droplet sizes corresponding to larger diameter growth factors $\left(\mathrm{GF}=d_{\mathrm{c}} / D_{\mathrm{p}}\right)$, and thus with more dilute total solute concentrations in the droplets $\left(c^{\mathrm{T}} \propto \mathrm{GF}^{-3}\right)$. However, the larger critical droplets also have smaller surface-area-to-bulk-volume ratios $\left(A / V \propto d_{\mathrm{c}}^{-1}\right)$ and are thus subject to relatively less bulkdepletion of surfactant from surface partitioning at a given total droplet composition. In addition to potentially influencing surfactant molecular properties, the presence of inorganic solutes directly affects critical droplet sizes, and thus total surfactant concentrations and surface-area-to-bulk-volume ratios, of activating droplets. The $\mathrm{CCN}$ properties of a given surfactant are therefore intricately linked to both dry particle size and composition. As a consequence, the variation in $\mathrm{CCN}$ activity with these dry particle properties is not readily anticipated, even when molecular properties of the individual aerosol components are known.

An example of these effects is shown in Fig. 1, for dry particles with diameters in the range $15-150 \mathrm{~nm}$ and comprising $80 \%$ by mass of surfactant (sodium dodecanoate, $\mathrm{C} 12 \mathrm{Na})$ mixed with sodium chloride $(\mathrm{NaCl})$. The values presented are calculated with a detailed thermodynamic model accounting for the surface partitioning equilibrium within activating droplets and have been adapted from the results presented in Figs. 6 and 7 of Prisle et al. (2009). Droplet surface tension is here evaluated as a function of surfactant and salt bulk molal concentrations $\left(m_{\mathrm{SFT}}^{\mathrm{B}}\right.$ and $\left.m_{\mathrm{NaCl}}^{\mathrm{B}}\right)$ from a ternary parametrization based on the Szyskowski equation (Prisle et al., 2009, and references therein):

$$
\begin{aligned}
\sigma & =\sigma_{\mathrm{w}}+\left(\frac{d \sigma_{\mathrm{NaCl}}}{d m_{\mathrm{NaCl}}^{\mathrm{B}}}\right) m_{\mathrm{NaCl}}^{\mathrm{B}}-a \ln \left(1+m_{\mathrm{C} 12 \mathrm{Na}}^{\mathrm{B}} / b\right), \\
a & =48.98-0.88 w_{\mathrm{C} 12 \mathrm{Na}}^{\mathrm{B}}, \\
b & =0.004+0.004 w_{\mathrm{C} 12 \mathrm{Na}}^{\mathrm{B}} .
\end{aligned}
$$

Here, parameters $a$ and $b$ depend on the relative C12Na and $\mathrm{NaCl}$ solute mass-fractions in the solution bulk phase, where $w_{\mathrm{C} 12 \mathrm{Na}}^{\mathrm{B}}+w_{\mathrm{NaCl}}^{\mathrm{B}}=1$, and $\sigma_{\mathrm{w}}=72.2 \mathrm{mN} \mathrm{m}^{-1}$ is the pure water surface tension at $296.65 \mathrm{~K}$. The surface tension gradient for aqueous $\mathrm{NaCl}$ is $\left(\frac{d \sigma_{\mathrm{NaCl}}}{d m_{\mathrm{NaCl}}^{\mathrm{B}}}\right)=1.61\left[\mathrm{mN} \mathrm{m}^{-1} / \mathrm{mol} \mathrm{kg}^{-1}\right]$ and accounts for a slight increase in solution surface tension arising directly from the inorganic ions.

Individual panels in Fig. 1 show values predicted at the point of activation for (a) droplet GF and $A / V$, (b) surfactant depletion from the droplet bulk in terms of the molar fraction of surfactant left in the bulk $\left(n_{\mathrm{C} 12 \mathrm{Na}}^{\mathrm{B}} / n_{\mathrm{C} 12 \mathrm{Na}}^{\mathrm{T}}\right)$ and the molar fraction of solute remaining in the bulk that is surfactant $\left(n_{\mathrm{C} 12 \mathrm{Na}}^{\mathrm{B}} /\left[n_{\mathrm{C} 12 \mathrm{Na}}^{\mathrm{B}}+n_{\mathrm{NaCl}}^{\mathrm{B}}\right]\right),(\mathrm{c})$ bulk-phase water mole fraction $\left(x_{\mathrm{w}}^{\mathrm{B}}\right)$ and water mole fraction with respect to only $\mathrm{NaCl}$ solute $\left(x_{\mathrm{w}, \mathrm{NaCl}}^{\mathrm{B}}\right)$, and (d) droplet surface tension, all as functions of dry particle diameter $\left(D_{\mathrm{p}}\right)$. Figure 1 illustrates how the surfactant molecules are largely depleted from the droplet bulk at the point of activation, due to partitioning to the surface phase $\left(n_{\mathrm{C} 12 \mathrm{Na}}^{\mathrm{B}} / n_{\mathrm{C} 12 \mathrm{Na}}^{\mathrm{T}} \sim 0.05\right)$. Even with the rather high surfactant mass fraction in the dry particles of the present example, the majority of solute in the droplet bulk at activation is $\mathrm{NaCl}\left(n_{\mathrm{C} 12 \mathrm{Na}}^{\mathrm{B}} /\left[n_{\mathrm{C} 12 \mathrm{Na}}^{\mathrm{B}}+n_{\mathrm{NaCl}}^{\mathrm{B}}\right] \sim 0.05\right)$. The effects on activating droplet solution properties are seen to be that both water activity and surface tension are significantly less affected by the organic solute than would be anticipated from its total concentration within the droplet, and are closer to the values predicted in the absence of surfactant solute. Similar results were obtained for other surfactants and dry particle component mixing ratios studied (Prisle et al., 2009).

\subsection{Critical supersaturation}

In the Köhler calculations, critical supersaturations $\left(S S_{\mathrm{c}}\right)$ are determined, for activating droplets formed on dry particles of given compositions and sizes, by iterating the respective maxima of the Köhler curves described by Eq. (1). Dry particles are assumed to be spherical and the particle volume is obtained from the diameter $\left(D_{\mathrm{p}}\right)$ as:

$V_{\mathrm{p}}=\frac{\pi}{6} D_{\mathrm{p}}^{3}$.

Particle compositions are given by the relative dry mass fractions $\left(W_{\mathrm{p}, i}\right)$ of organic surfactant $(i=\mathrm{SFT})$ and inorganic salt $(i=\mathrm{s})$, where $W_{\mathrm{p}, \mathrm{SFT}}+W_{\mathrm{p}, \mathrm{s}}=1$. Assuming volume additivity of the individual dry particle components, the total molar amounts $\left(n_{i}^{\mathrm{T}}\right)$ of each solute $(i=\mathrm{SFT}, \mathrm{s})$ available in the droplets are then:

$n_{i}^{\mathrm{T}}=\frac{W_{\mathrm{p}, i}}{M_{i}} \frac{\pi}{6} D_{\mathrm{p}}^{3}\left(\frac{W_{\mathrm{p}, \mathrm{SFT}}}{\rho_{\mathrm{SFT}}}+\frac{W_{\mathrm{p}, \mathrm{s}}}{\rho_{\mathrm{s}}}\right)^{-1}$.

Here, $\rho_{\mathrm{SFT}}$ and $\rho_{\mathrm{S}}$ are the respective mass densities of pure solid organic surfactant and inorganic salt, and $M_{i}$ is the molar mass of each component.

Complete dissolution of each dry particle component, and volume additivity of water and all solutes, is assumed within the aqueous droplets formed. The increasing total molar 
(a) $80 \% \mathrm{C} 12 \mathrm{Na}+20 \% \mathrm{NaCl}$ critical droplets

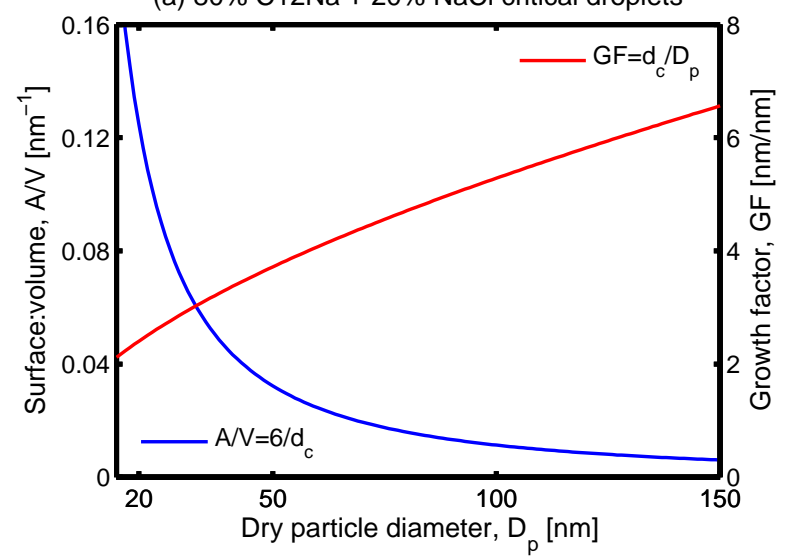

(c) $80 \% \mathrm{C} 12 \mathrm{Na}+20 \% \mathrm{NaCl}$ critical droplets

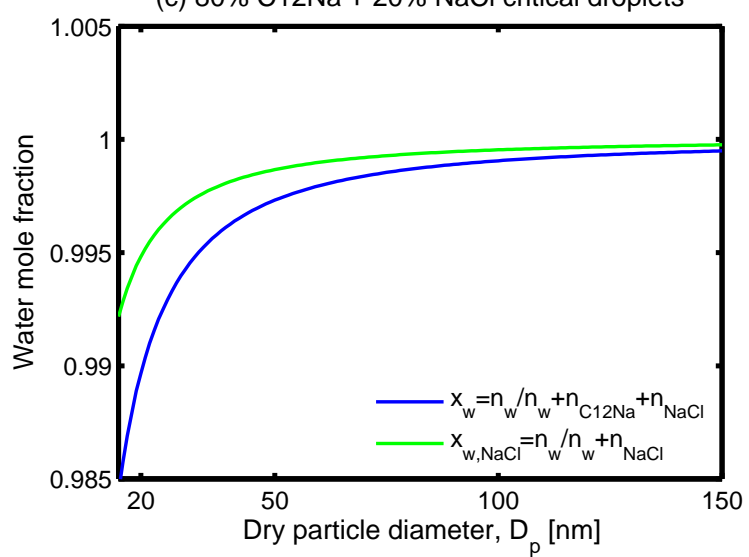

(b) $80 \% \mathrm{C} 12 \mathrm{Na}+20 \% \mathrm{NaCl}$ critical droplets

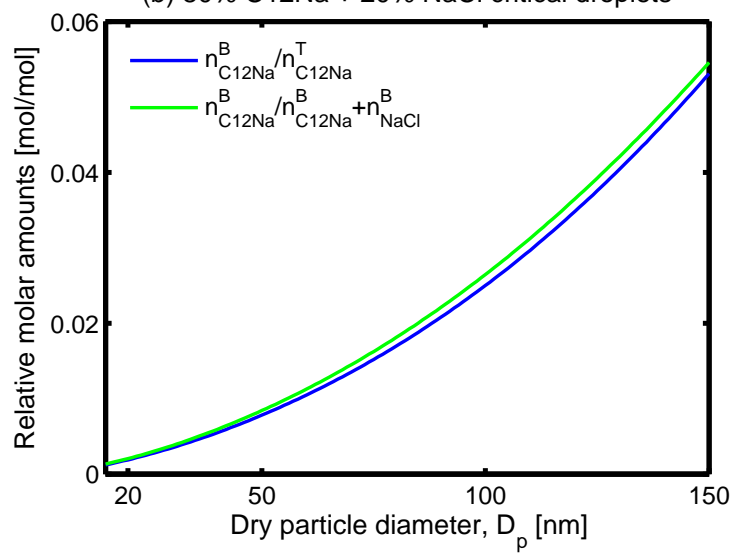

(d) $80 \% \mathrm{C} 12 \mathrm{Na}+20 \% \mathrm{NaCl}$ critical droplets

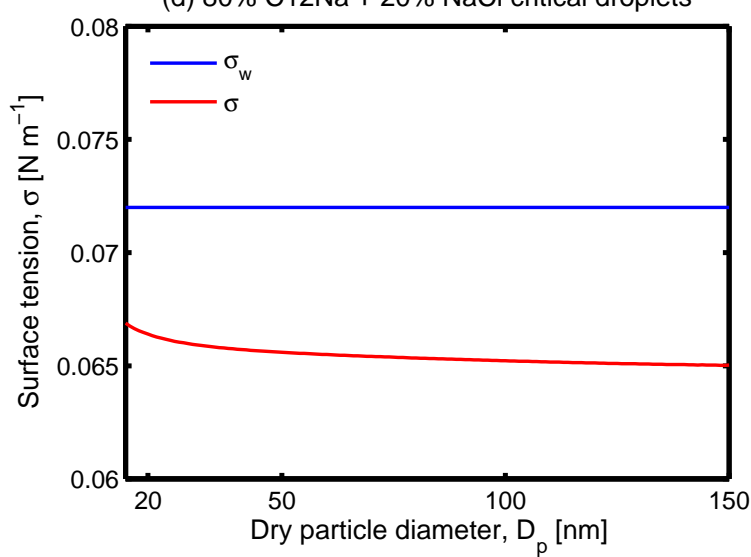

Fig. 1. Selected properties, predicted at the point of droplet activation, for spherical dry particles comprising $80 \%$ by mass of surfactant (sodium dodecanoate, $\mathrm{C} 12 \mathrm{Na}$ ) mixed with sodium chloride ( $\mathrm{NaCl}$ ): (a) diameter growth factor (GF) and droplet surface-area-to-bulk-volume ratio $(A / V)$, (b) molar fraction of surfactant left in the droplet bulk $\left(n_{\mathrm{C} 12 \mathrm{Na}}^{\mathrm{B}} / n_{\mathrm{C} 12 \mathrm{Na}}^{\mathrm{T}}\right)$ and molar fraction of total solute in the droplet bulk that is surfactant $\left(n_{\mathrm{C} 12 \mathrm{Na}}^{\mathrm{B}} /\left[n_{\mathrm{C} 12 \mathrm{Na}}^{\mathrm{B}}+n_{\mathrm{NaCl}}^{\mathrm{B}}\right]\right)$, (c) bulk-phase water mole fraction $\left(x_{\mathrm{W}}^{\mathrm{B}}\right)$ and water mole fraction with respect to only NaCl solute $\left(x_{\mathrm{w}, \mathrm{NaCl}}^{\mathrm{B}}\right)$, (d) droplet surface tension $(\sigma)$, together with the surface tension of pure water $\left(\sigma_{\mathrm{w}}\right)$. Values are presented as functions of dry particle diameter $\left(D_{\mathrm{p}}\right)$ and have been adapted from Prisle et al. (2009).

amount of water $\left(n_{\mathrm{w}}^{\mathrm{T}}\right)$ in a growing droplet is then calculated as a function of the diameter $(d)$ according to:

$n_{\mathrm{w}}^{\mathrm{T}}=\frac{\rho_{\mathrm{w}}}{M_{\mathrm{w}}} \frac{\pi}{6}\left(d^{3}-D_{\mathrm{p}}^{3}\right)$.

Both water activity and surface tension are determined from the droplet solution bulk-phase composition, such that $a_{\mathrm{w}}=a_{\mathrm{w}}^{\mathrm{B}}\left(n_{i}^{\mathrm{B}}, n_{\mathrm{w}}^{\mathrm{B}}\right)$ and $\sigma=\sigma^{\mathrm{B}}\left(n_{i}^{\mathrm{B}}, n_{\mathrm{w}}^{\mathrm{B}}\right)$.

In the detailed model accounting for the surfactant partitioning equilibrium (Prisle et al., 2010, and references therein), droplet bulk-phase molar composition $\left(n_{i}^{\mathrm{B}}, n_{\mathrm{w}}^{\mathrm{B}}\right)$ is determined for each droplet size and corresponding total composition $\left(n_{i}^{\mathrm{T}}, n_{\mathrm{w}}^{\mathrm{T}}\right)$ by solving the partitioning equilibrium numerically. The droplet bulk-phase water activity is subsequently set equal to the corresponding water mole-fraction concentration $\left(a_{\mathrm{w}}^{\mathrm{B}}=x_{\mathrm{w}}^{\mathrm{B}}\right)$, equivalent to assuming ideal water mixing properties in solution (unit water activity coefficient, $\gamma_{\mathrm{w}}^{\mathrm{B}}=1$ ), and the droplet surface tension is evaluated from concentration-dependent parametrizations for ternary aqueous solutions analogous to the one given in Eq. (5). This information is generally not available for complex aerosol mixtures, let alone for particles of unresolved composition, just as the method of solving the partitioning equilibrium numerically cannot be applied in its current form to droplets with more than a total of three components. The detailed model is therefore currently not applicable to more realistic particle systems, such as smog-chamber generated secondary organic aerosol (SOA) or ambient aerosol, with unresolved organic composition and/or molecular properties in solution. 


\subsection{Simple organic representation}

Motivated by knowledge of the behavior of organic surfactants in activating solution droplets, gained from the detailed thermodynamic model (as illustrated in Fig. 1), we here introduce a very simple representation to account for the cloud droplet activation properties of such surface active organic aerosols. This simple representation (abbreviated "rep1" in the following) just assumes all surface active organics are partitioned to the droplet surface, and thus have no net effect on either water activity or surface tension of the droplet solution, at the point of activation. Specifically, the molar amount of surfactant in the droplet bulk-phase is set to

$n_{\mathrm{SFT}}^{\mathrm{B}}=0$.

It is implied that the division of the bulk and surface phases is such that neither the inorganic, nor water, partition to the droplet surface, whence

$n_{\mathrm{s}}^{\mathrm{B}}=n_{\mathrm{s}}^{\mathrm{T}}$,

$n_{\mathrm{w}}^{\mathrm{B}}=n_{\mathrm{w}}^{\mathrm{T}}$.

The bulk-phase water mole fraction is then

$x_{\mathrm{w}}^{\mathrm{B}} \equiv \frac{n_{\mathrm{w}}^{\mathrm{B}}}{n_{\mathrm{w}}^{\mathrm{B}}+n_{\mathrm{s}}^{\mathrm{B}}+n_{\mathrm{SFT}}^{\mathrm{B}}}=\frac{n_{\mathrm{w}}^{\mathrm{B}}}{n_{\mathrm{w}}^{\mathrm{B}}+n_{\mathrm{s}}^{\mathrm{B}}}=\frac{n_{\mathrm{w}}^{\mathrm{T}}}{n_{\mathrm{w}}^{\mathrm{T}}+n_{\mathrm{s}}^{\mathrm{T}}} \equiv x_{\mathrm{w}, \mathrm{s}}^{\mathrm{T}}$,

where $x_{\mathrm{w}, \mathrm{s}}$ is the water mole fraction with respect to only inorganic solute. The corresponding droplet water activity is then

$a_{\mathrm{w}}=a_{\mathrm{w}}\left(x_{\mathrm{w}, \mathrm{s}}^{\mathrm{T}}\right)=x_{\mathrm{w}, \mathrm{s}}^{\mathrm{T}}$

Substituting the vanishing bulk concentration of surfactant resulting from Eq. (11) into an appropriate concentrationdependent surface tension parametrization, analogous to that given in Eq. (5), and neglecting any direct influence on surface tension from the inorganic salt $\left(\frac{d \sigma_{\mathrm{NaCl}}}{d m_{\mathrm{NaCl}}^{\mathrm{B}}}=0\right)$, the droplet surface tension is simply that of pure water at the given activation temperature

$\sigma=\sigma_{\mathrm{w}}$

The assumption of complete organic surface partitioning is essentially just the simplest conceivable parametrization of a solution to the partitioning equilibrium at the point of droplet activation. The implications for Köhler calculations are analogous to treating the entire organic particle fraction as an insoluble, fully wettable core within the activating droplet; however, the view of complete partitioning to the droplet surface is clearly thermodynamically more consistent in the case of a surface active organic displaying some finite water solubility. Although it may seem contradictory that a soluble and surface active solute in effect has no influence on neither water activity nor surface tension of the droplets, activation properties approaching those following from Eqs. (15) and
(16) are exactly the outcome of the detailed model predictions. Notably, the expected consequences for surface active organic $\mathrm{CCN}$ properties have been demonstrated experimentally for a number of compounds (Prisle et al., 2008, 2010; Sorjamaa et al., 2004). For the present purposes of a simplified description, the modest effects of the organic solute on either surface tension or water activity of the activating droplets, as seen in Fig. 1, are thus neglected altogether.

The complete surface partitioning of surfactant molecules is a consequence of the large surface-area-to-bulk-volume ratios $(A / V)$ of microscopic activating droplets, compared to macroscopic solutions, as explained in more detail by Prisle et al. (2010). The equilibrium concentration gradient in the anisotropic surface leaves essentially no surfactant solute in the isotropic droplet bulk. However, the surfactant density in the surface phase is still insufficient to enable molecular interactions that significantly reduce solution surface tension, compared to pure water, even when the majority of surfactant molecules are partitioned to the droplet surface. The solution surface tension is fundamentally determined by molecular interactions within the surface phase, but is typically parametrized as a function of the bulk phase composition, as must be valid at equilibrium between the two phases.

Using the simple organic representation presented here, the droplet bulk-phase composition and properties are obtained directly from the total composition, according to Eqs. (11)-(16) above, without iterations of a numerical solution to the surface partitioning equilibrium. This makes the Köhler calculations computationally much less demanding, which is essential for considering these effects in large scale atmospheric models. Furthermore, using the simple representation only requires knowledge of the total organic aerosol mass fraction, as well as the average density of this fraction (for use in Eq. (9) when $i=\mathrm{s}$ ). Both of these quantities can be measured directly with available techniques. In particular, the simple representation does not require the identity and properties of the organic molecular components to be known (since these are assumed to not affect the properties of the activating droplets), making this representation potentially applicable to surface active organic aerosol of unresolved composition or composition-dependent molecular properties.

\section{Results and discussion}

The CCN activity of particles comprising one of the surfactants sodium octanoate $\left(\mathrm{CH}_{3}\left(\mathrm{CH}_{2}\right)_{6} \mathrm{COONa} ; \mathrm{C} 8 \mathrm{Na}\right)$, sodium decanoate $\left(\mathrm{CH}_{3}\left(\mathrm{CH}_{2}\right)_{8} \mathrm{COONa} ; \mathrm{C} 10 \mathrm{Na}\right)$, sodium dodecanoate $\left(\mathrm{CH}_{3}\left(\mathrm{CH}_{2}\right)_{10} \mathrm{COONa} ; \mathrm{C} 12 \mathrm{Na}\right)$, or sodium dodecyl sulfate $\left(\mathrm{CH}_{3}\left(\mathrm{CH}_{2}\right)_{11} \mathrm{OSO}_{3} \mathrm{Na}\right.$; SDS), mixed with $\mathrm{NaCl}$, was studied in laboratory experiments and modeled from Köhler theory accounting for the surface partitioning equilibrium by Prisle et al. (2010). For comparison with these results, Köhler calculations using the simple organic 
(a) Mixed $\mathrm{C} 8 \mathrm{Na}+\mathrm{NaCl}$ particles

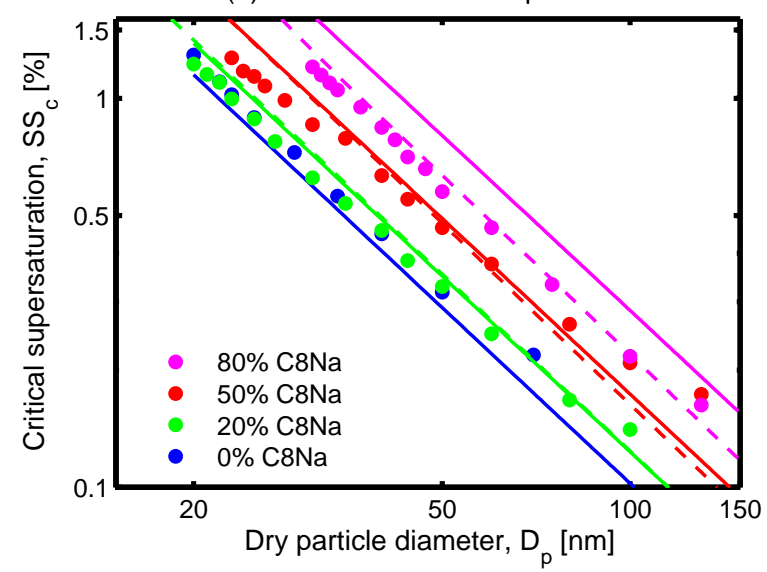

(b) Mixed $\mathrm{C} 8 \mathrm{Na}+\mathrm{NaCl}$ particles

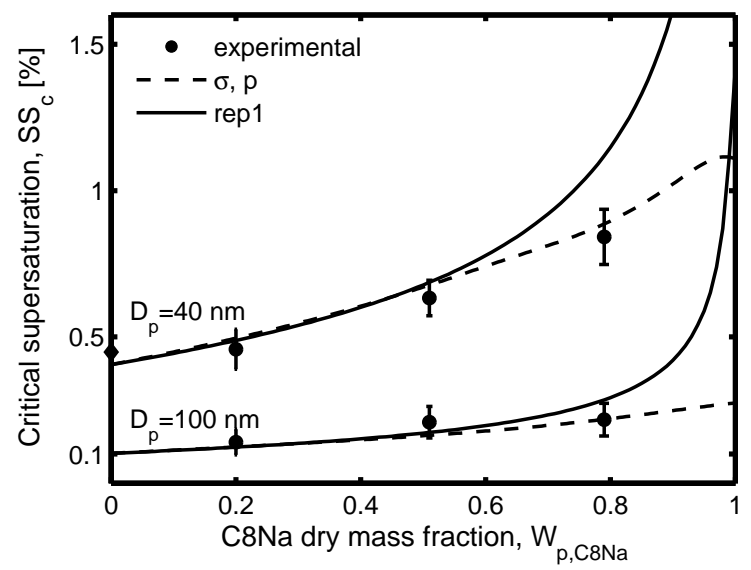

Fig. 2. Critical supersaturations $\left(S S_{\mathrm{c}}[\%]\right)$ for particles comprising sodium octanoate $(\mathrm{C} 8 \mathrm{Na})$ mixed with sodium chloride $(\mathrm{NaCl})$, as functions of (a) dry particle diameter $\left(D_{\mathrm{p}}[\mathrm{nm}]\right)$, and (b) dry particle surfactant mass fraction $\left(W_{\mathrm{p}, \mathrm{C} 8 \mathrm{Na}}\right)$. Results are shown for particles with selected dry surfactant mass fractions in panel (a), and for dry particle sizes of $D_{\mathrm{p}}=40 \mathrm{~nm}$ (upper curves and data points) and $D_{\mathrm{p}}=100 \mathrm{~nm}$ (lower curves and data points) in panel (b). In both figures, points are experimental values, dashed lines are calculated with the detailed thermodynamic model $(\sigma, \mathrm{p})$, both adapted from Prisle et al. (2010), and solid lines are calculated with the simple organic representation (rep1).

representation (rep1) were here made assuming ideal water mixing properties in the droplet solutions (unit water activity coefficient, $\gamma_{\mathrm{w}}^{\mathrm{B}}=1$ ), such that

$a_{\mathrm{w}}=x_{\mathrm{w}, \mathrm{s}}^{\mathrm{T}}=\frac{n_{\mathrm{w}}^{\mathrm{T}}}{n_{\mathrm{w}}^{\mathrm{T}}+\delta_{\mathrm{NaCl}} n_{\mathrm{NaCl}}^{\mathrm{T}}}$.

$\mathrm{NaCl}$ was assumed to be fully dissociated by using a constant dissociation factor $\delta_{\mathrm{NaCl}}=2$ in Eq. (17). The partial molar volume of water $\left(v_{\mathrm{w}}\right)$ was approximated with the molar volume of pure water, given by the water molar mass and mass density as $\nu_{\mathrm{w}}^{0}=M_{\mathrm{w}} / \rho_{\mathrm{w}}$, according to the assumption of ideal mixing volume for water within the droplets. Mass densities used for the organics were $\rho_{\mathrm{C} 8 \mathrm{Na}}=\rho_{\mathrm{C} 10 \mathrm{Na}}=\rho_{\mathrm{C} 12 \mathrm{Na}}=1.2 \mathrm{~g} \mathrm{~cm}^{-3}$ and $\rho_{\mathrm{SDS}}=1.176 \mathrm{~g} \mathrm{~cm}^{-3}$, and for the salt $\rho_{\mathrm{NaCl}}=2.165 \mathrm{~g} \mathrm{~cm}^{-3}$. The temperature was $T=296.65 \mathrm{~K}$.

Results are shown in Figs. 2, 3, 4, and 5, for particles comprising C8Na, C10Na, C12Na, and SDS, respectively, mixed with $\mathrm{NaCl}$. In each figure, panel (a) shows critical supersaturations $\left(S S_{\mathrm{c}}\right)$ as functions of dry particle diameter $\left(D_{\mathrm{p}}\right)$, for particles with dry surfactant mass fractions of $0 \%$ (blue), $20 \%$ (green), $50 \%$ (red), and 80\% (purple), and in panel (b), critical supersaturations are shown as functions of dry particle surfactant mass fraction $\left(W_{\mathrm{p}, \mathrm{SFT}}\right)$ for particle diameters of 40 and $100 \mathrm{~nm}$. Calculations with rep1 are shown as solid lines, and the results of Prisle et al. (2010) from experiments and calculations using the detailed partitioning model $(\sigma, \mathrm{p})$ are shown as points and dashed lines, respectively. Overall, very good agreement between critical supersaturations calculated using the simple organic representation and both experimental values and detailed model predictions is seen for particles with up to at least $50 \%$ by mass of surfactant, and for particles comprising $\mathrm{C} 10 \mathrm{Na}, \mathrm{C} 12 \mathrm{Na}$ and SDS even up to at least $80 \%$ surfactant.

Surfactant strength, as quantified in Eq. (4) above, for the $\mathrm{C} 8 \mathrm{Na}-\mathrm{C} 12 \mathrm{Na}$ fatty acid salts and SDS increases in the order of increasing molar mass, $M_{\mathrm{C} 8 \mathrm{Na}}<M_{\mathrm{C} 10 \mathrm{Na}}<M_{\mathrm{C} 12 \mathrm{Na}}<M_{\mathrm{SDS}}$ (Prisle et al., 2010, 2008, and references therein). The agreement of predictions using rep1 with both experiments and the detailed model increases with the surfactant strength, as expected; the stronger surfactants are relatively more partitioned to the droplet surface, yet the effect on droplet activation of the surface tension reduction attained evidently cannot overcome that of increased water activity due to bulkdepletion of surfactant solute (Prisle et al., 2010). As the strength of these surfactants increases, the effect is described still better by Eq. (11), yet still poorer by Eq. (16); however, the combined effects of surface activity on CCN properties are dominated by the first mechanism, rather than the latter. For particles comprising the stronger surfactants $\mathrm{C} 12 \mathrm{Na}$ and SDS, the agreement of rep1 with experiments and the detailed model is very good over the full range of surfactantsalt mixing ratios shown in Figs. $4 \mathrm{a}$ and $5 \mathrm{a}$.

With the weaker surfactant C8Na, using the simple representation overpredicts critical supersaturations for particles with $80 \%$ surfactant. Likely, C8Na is not sufficiently surface active for the majority of these molecules to be effectively partitioned to the droplet surface, at the concentrations attained for activating droplets formed on particles with this high dry surfactant mass fraction. In general, the simple organic representation is not expected to work for weak surfactants; these organics will only be partially partitioned to the solution surface and some effect of the resulting finite organic bulk concentrations on droplet water activity 
(a) Mixed $\mathrm{C} 10 \mathrm{Na}+\mathrm{NaCl}$ particles

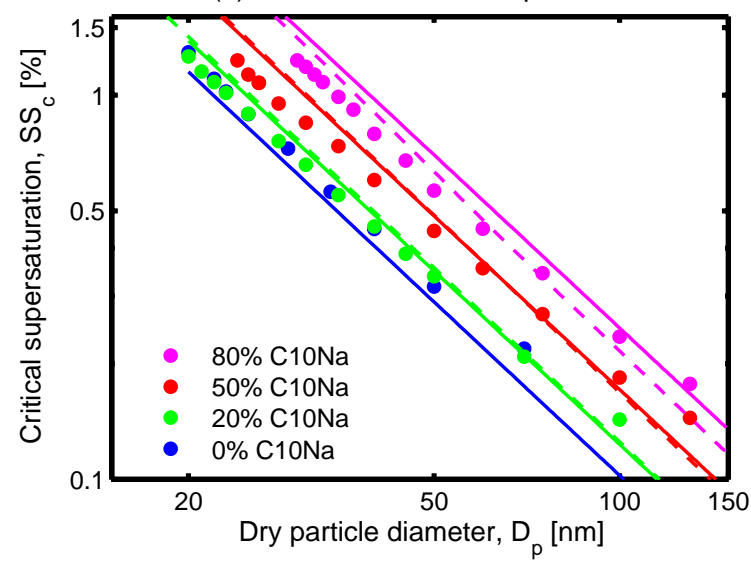

(b) Mixed $\mathrm{C} 10 \mathrm{Na}+\mathrm{NaCl}$ particles

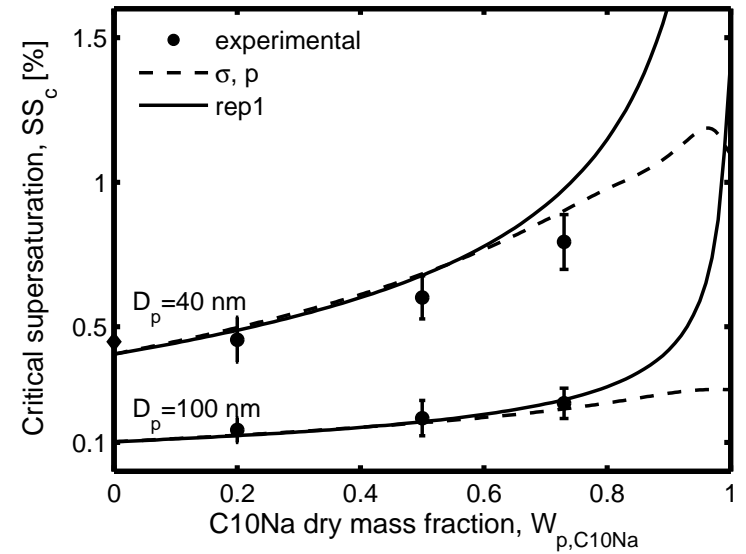

Fig. 3. Critical supersaturations $\left(S S_{\mathrm{c}}[\%]\right)$ for particles comprising sodium decanoate $(\mathrm{C} 10 \mathrm{Na})$ mixed with sodium chloride $(\mathrm{NaCl})$, as functions of (a) dry particle diameter $\left(D_{\mathrm{p}}[\mathrm{nm}]\right)$, and (b) dry particle surfactant mass fraction $\left(W_{\mathrm{p}, \mathrm{C} 10 \mathrm{Na}}\right)$. Results are shown for particles with selected dry surfactant mass fractions in panel (a), and for dry particle sizes of $D_{\mathrm{p}}=40 \mathrm{~nm}$ (upper curves and data points) and $D_{\mathrm{p}}=100 \mathrm{~nm}$ (lower curves and data points) in panel (b). In both figures, points are experimental values, dashed lines are calculated with the detailed thermodynamic model ( $\sigma, \mathrm{p})$, both adapted from Prisle et al. (2010), and solid lines are calculated with the simple organic representation (rep1).

(a) Mixed $\mathrm{C} 12 \mathrm{Na}+\mathrm{NaCl}$ particles

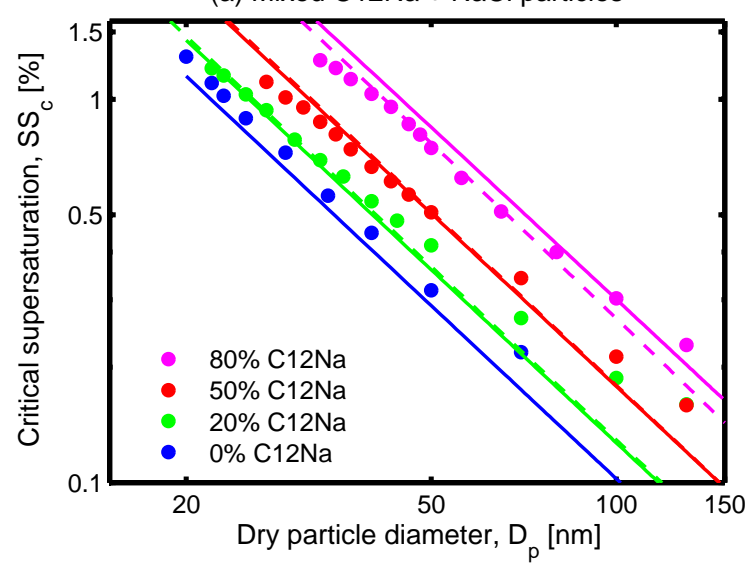

(b) Mixed $\mathrm{C} 12 \mathrm{Na}+\mathrm{NaCl}$ particles

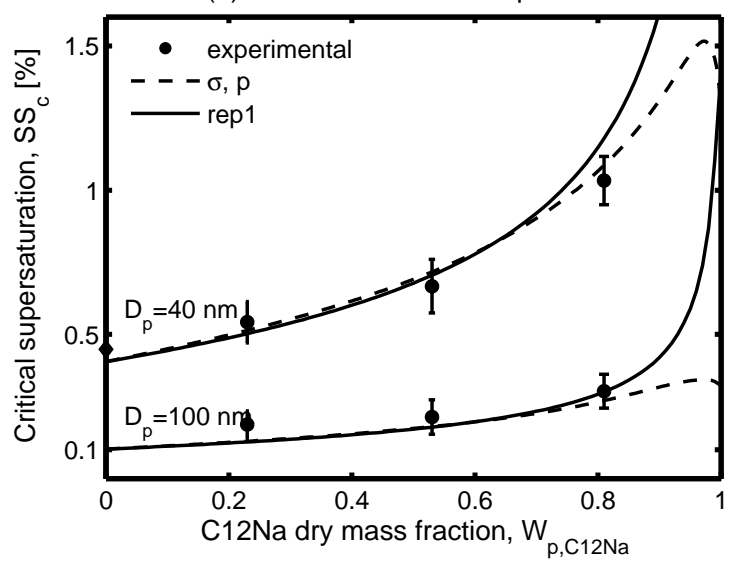

Fig. 4. Critical supersaturations $\left(S S_{\mathrm{c}}[\%]\right)$ for particles comprising sodium dodecanoate $(\mathrm{C} 12 \mathrm{Na})$ mixed with sodium chloride $(\mathrm{NaCl})$, as functions of (a) dry particle diameter $\left(D_{\mathrm{p}}[\mathrm{nm}]\right)$, and (b) dry particle surfactant mass fraction $\left(W_{\mathrm{p}, \mathrm{C} 12 \mathrm{Na}}\right)$. Results are shown for particles with selected dry surfactant mass fractions in panel (a), and for dry particle sizes of $D_{\mathrm{p}}=40 \mathrm{~nm}$ (upper curves and data points) and $D_{\mathrm{p}}=100 \mathrm{~nm}$ (lower curves and data points) in panel (b). In both figures, points are experimental values, dashed lines are calculated with the detailed thermodynamic model $(\sigma, \mathrm{p})$, both adapted from Prisle et al. (2010), and solid lines are calculated with the simple organic representation (rep1).

$\left(x_{\mathrm{w}}^{\mathrm{B}}<x_{\mathrm{w}, \mathrm{s}}^{\mathrm{T}}\right)$, in combination with a possible slight surface tension reduction $\left(\sigma<\sigma_{\mathrm{w}}\right)$, may therefore be anticipated in activating droplets containing these molecules.

For increasing surfactant mass fractions in the dry particles, the simple organic representation eventually overpredicts critical supersaturations, as is clearly seen in Figs. 2b, $3 \mathrm{~b}, 4 \mathrm{~b}$, and $5 \mathrm{~b}$. A number of surface active organics have been demonstrated in previous experimental and theoretical works to act as efficient $\mathrm{CCN}$ in single-component particles under atmospherically relevant conditions (Prisle et al., 2008; Sorjamaa et al., 2004). As dry particle surfactant mass fractions increase, critical supersaturations generally increase, and activating droplets become smaller and more concentrated. Eventually, the position of the partitioning equilibrium does leave some surfactant solute in the bulk at droplet activation, thus resulting in some reduction in droplet surface tension and/or water activity. In the limit of aerosol consisting purely of water soluble surfactant, some of this solute 
(a) Mixed SDS + $\mathrm{NaCl}$ particles

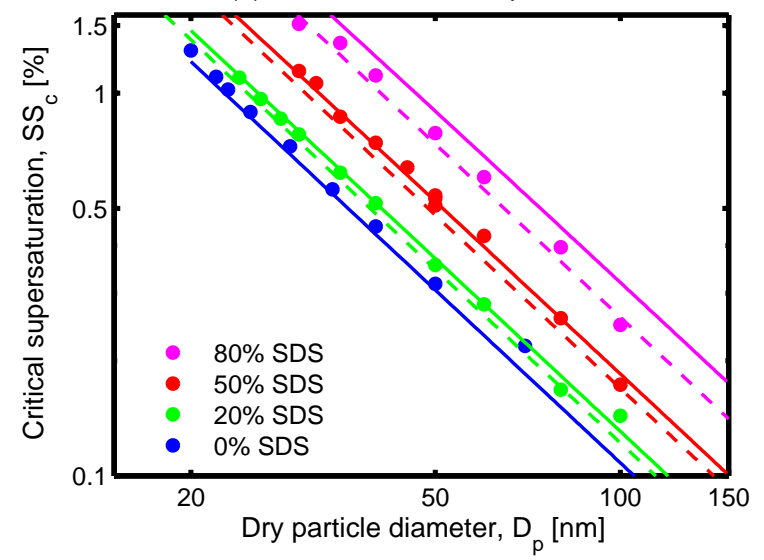

(b) Mixed SDS + $\mathrm{NaCl}$ particles

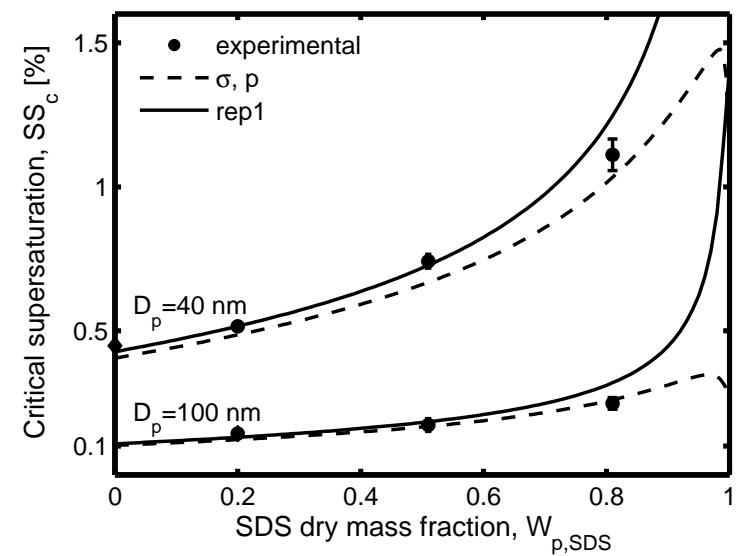

Fig. 5. Critical supersaturations $\left(S S_{\mathrm{c}}[\%]\right)$ for particles comprising sodium dodecyl sulfate (SDS) mixed with sodium chloride (NaCl), as functions of (a) dry particle diameter $\left(D_{\mathrm{p}}[\mathrm{nm}]\right)$, and (b) dry particle surfactant mass fraction $\left(W_{\mathrm{p}, \mathrm{SDS}}\right)$. Results are shown for particles with selected dry surfactant mass fractions in panel (a), and for dry particle sizes of $D_{\mathrm{p}}=40 \mathrm{~nm}$ (upper curves and data points) and $D_{\mathrm{p}}=100 \mathrm{~nm}$ (lower curves and data points) in panel (b). In both figures, points are experimental values, dashed lines are calculated with the detailed thermodynamic model $(\sigma, \mathrm{p})$, both adapted from Prisle et al. (2010), and solid lines are calculated with the simple organic representation (rep1).

may likewise be expected to remain dissolved in the droplet bulk. These situations are innately not captured by the simple representation, effectively treating the organic as an insoluble, but wettable, core/surface; the simple organic representation is therefore not expected to be applicable to pure organic particles of water soluble surfactants. In the context of atmospheric modeling, however, such particle compositions are unlikely to be representative of ambient aerosol, which are generally found to be mixtures of both organic and inorganic species (Murphy et al., 2006; O’Dowd et al., 2004). The surfactant-salt particles that are seen here to be well described by the simple organic representation cover the range of organic-inorganic mixing ratios typically seen in the atmosphere (Zhang et al., 2007).

The errors in predicted critical supersaturations $\left(S S_{\mathrm{c}}\right)$, relative to the experimental values $\left(S S_{\mathrm{c}}^{\mathrm{exp}}\right)$ measured by Prisle et al. (2010),

$S S_{\mathrm{c}}$ relative error $=\frac{S S_{\mathrm{c}}-S S_{\mathrm{c}}^{\exp }}{S S_{\mathrm{c}}^{\exp }}$,

are shown in Fig. 6. Individual panels show results as functions of dry particle diameter $\left(D_{\mathrm{p}}\right)$ for particles comprising (a) $\mathrm{C} 8 \mathrm{Na}$, (b) $\mathrm{C} 10 \mathrm{Na}$, (c) $\mathrm{C} 12 \mathrm{Na}$, and (d) SDS. Open symbols correspond to predictions made with the detailed thermodynamic model $(\sigma, \mathrm{p})$ and filled symbols are for predictions with the simple organic representation (rep1). Dry particle surfactant mass fractions are indicated by the symbol colors as $0 \%$ (blue), $20 \%$ (green), $50 \%$ (red), and $80 \%$ (purple).

Figure 6 emphasizes the results in Figs. 2, 3, 4, and 5, in terms of the performance of the simple organic representation, compared to the detailed thermodynamic model ac- counting for the partitioning equilibrium. The detailed model generally describes experimental observations better than the simple representation, as expected. Nevertheless, predictions of the latter are comparable to those of the detailed model, for all but the weakest of the four surfactants $(\mathrm{C} 8 \mathrm{Na})$, and dry particles with the very highest organic mass fractions (80\%) shown. The simple two-component aerosols shown here can be regarded as model systems for marine aerosol (O'Dowd et al., 2004). The range of applicability for the simple representation to surfactants with different strength and molecular properties, and to particles with different mixing states, in terms of both nature of the inorganic salt and organic mass fraction needs to be investigated in more detail in future work. Currently, the availability of both laboratory data and detailed model predictions of CCN activity for mixed surfactant-salt particle systems is however still limited.

Contrary to the detailed thermodynamic model, the simple organic representation proposed here does not require composition and molecular properties of the organic particle fraction to be known; specifically, only the magnitude and mass density of this organic fraction is required, both of which can be measured directly with available techniques. The simple representation therefore has potential for application to complex and realistic surface active organic aerosols, such as the before-mentioned smog-chamber generated SOA, and ambient aerosol. Notably, this representation is only aimed at describing the resulting CCN potential of surface active organics, and in particular it is not assumed to represent the general properties of the organic aerosol system. It is furthermore not intended to replace analytical solutions to the partitioning equilibrium derived from thermodynamic 
(a) Mixed $\mathrm{C} 8 \mathrm{Na}+\mathrm{NaCl}$ particles

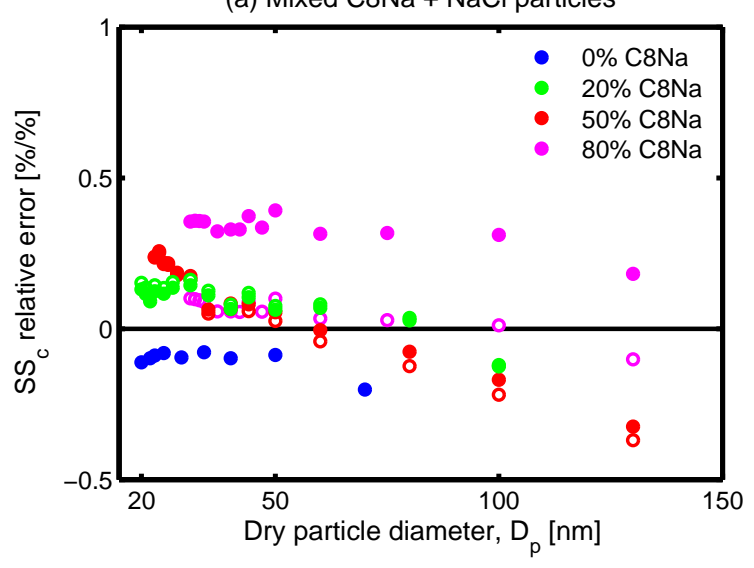

(c) Mixed $\mathrm{C} 12 \mathrm{Na}+\mathrm{NaCl}$ particles

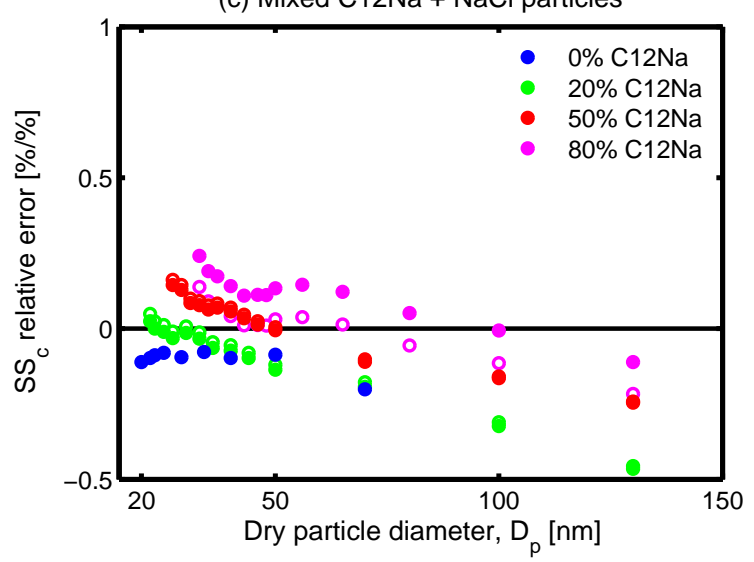

(b) Mixed $\mathrm{C} 10 \mathrm{Na}+\mathrm{NaCl}$ particles

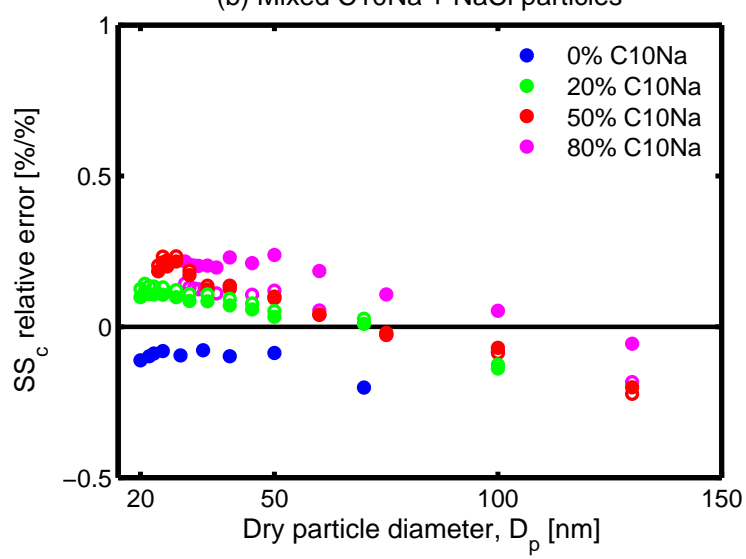

(d) Mixed SDS $+\mathrm{NaCl}$ particles

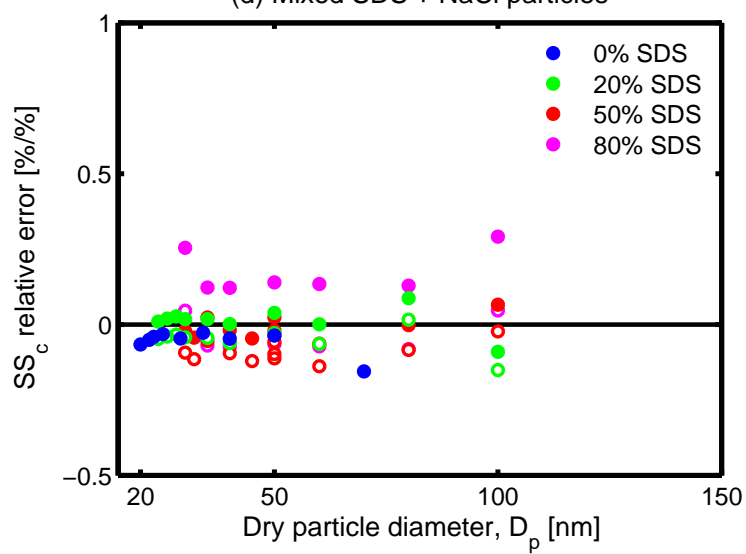

Fig. 6. Relative errors in predicted critical supersaturations $\left.\left(S S_{\mathrm{c}}-S S_{\mathrm{c}}^{\exp }\right) / S S_{\mathrm{c}}^{\exp }[\% / \%]\right)$ with the detailed thermodynamic model $(\sigma, \mathrm{p}$, open symbols) and the simple organic representation (rep1, filled symbols), as functions of dry particle diameter $\left(D_{\mathrm{p}}[\mathrm{nm}]\right)$, for particles comprising (a) sodium octanoate $(\mathrm{C} 8 \mathrm{Na})$, (b) sodium decanoate $(\mathrm{C} 10 \mathrm{Na})$, (c) sodium dodecanoate $(\mathrm{C} 12 \mathrm{Na})$, and (d) sodium dodecyl sulfate (SDS). Dry particle surfactant mass fractions are indicated by the color of symbols as $0 \%$ (blue), 20\% (green), 50\% (red), and 80\% (purple). Results correspond to those shown in Figs. 2, 3, 4, and 5.

relations. This simple representation rather presents an alternative to such approaches with potential application to complex aerosol systems, for which the properties required for analytical solutions are not yet available. Moreover, calculations using the simple representation are computationally much less demanding than the detailed partitioning model and should therefore be as applicable to large scale cloud modeling as the analytical solutions presented by Topping (2010) and Raatikainen and Laaksonen (2010).

\section{Conclusions}

A simple representation for the cloud droplet activation properties of surface active organics is introduced and applied in Köhler predictions for mixed organic-inorganic aerosol particles. Results of these calculations are compared against lab- oratory measurements, as well as model predictions based on detailed thermodynamic relations, of the CCN activity for corresponding mixed aerosols from the literature. The simple organic representation is seen to work well for particle organic-inorganic composition ranges corresponding to those typically found in the atmosphere. As expected, the agreement with both experiments and detailed model predictions increases with surfactant strength. For all but the weakest surfactant and highest organic aerosol fractions, the simple representation closely follows the performance of the detailed thermodynamic model in capturing observed droplet activation for the studied particle mixtures. Contrary to the detailed model, the proposed simple organic representation does not require knowledge of either composition or composition-dependent molecular properties for the organic aerosol fraction and consequently has potential for application to complex and realistic surface active organic aerosols. 
The simple representation is not computationally demanding and therefore also has high potential for implementation to atmospheric models accounting for cloud microphysics.

Acknowledgements. N. L. Prisle gratefully acknowledges the funding received for this work from the Carlsberg Foundation (grant 2009_01_0366).

Edited by: M. Kulmala

\section{References}

Asa-Awuku, A., Sullivan, A. P., Hennigan, C. J., Weber, R. J., and Nenes, A.: Investigation of molar volume and surfactant characteristics of water-soluble organic compounds in biomass burning aerosol, Atmos. Chem. Phys., 8, 799-812, doi:10.5194/acp-8799-2008, 2008.

Bianco, H. and Marmur, A.: The dependence of the surface tension of surfactant solutions on drop size, J. Colloid Interf. Sci., 151, 517-522, 1992.

Cheng, Y., Li, S.-M., Leithead, A., Brickell, P. C., and Leaitch, W. R.: Characterizations of cis-pinonic acid and n-fatty acids on fine aerosols in the Lower Fraser Valley during Pacific 2001 air quality study, Atmos. Environ., 38, 5789-5800, 2004.

Dinar, E., Taraniuk, I., Graber, E. R., Katsman, S., Moise, T., Anttila, T., Mentel, T. F., and Rudich, Y.: Cloud Condensation Nuclei properties of model and atmospheric HULIS, Atmos. Chem. Phys., 6, 2465-2482, doi:10.5194/acp-6-2465-2006, 2006.

Facchini, M., Mircea, M., Fuzzi, S., and Charlson, R.: Cloud albedo enhancement by surface-active organic solutes in growing droplets, Nature, 401, 257-259, 1999.

Facchini, M., Decesari, S., Mircea, M., Fuzzi, S., and Loglio, G.: Surface tension of atmospheric wet aerosol and cloud/fog droplets in relation to their organic carbon content and chemical composition, Atmos. Environ., 34, 4853-4857, 2000.

Gibbs, J., Bumstead, H., Longley, W., and Name, R. V.: The Collected Works of J. Willard Gibbs, Longmans, Green and Co., 1928.

IPCC: Climate Change 2007, The Physical Science Basis, Contribution of Working Group I to the Fourth Assessment Report of the Intergovernmental Panel on Climate Change, Cambridge University Press, New York, USA, 2007.

Kiss, G., Tombacz, E., and Hansson, H.-C.: Surface tension effects of humic-like substances in the aqueous extract of tropospheric fine aerosol, J. Atmos. Chem., 50, 279-294, 2005.

Köhler, H.: The nucleus in and the growth of hygroscopic droplets, T. Faraday Soc., 32, 1152-1161, 1936.

Kokkola, H., Sorjamaa, R., Peräniemi, A., Raatikainen, T., and Laaksonen, A.: Cloud formation of particles containing humiclike substances, Geophys. Res. Lett., 33, L10816, 1-5, 2006.

Laaksonen, A.: The composition size dependence of aerosols created by dispersion of surfactant solutions, J. Colloid Interf. Sci., 159, 517-519, 1993.

Lin, B., McCormick, A. V., Davis, H. T., and Strey, R.: Solubility of sodium soaps in aqueous salt solutions, J. Colloid Interf. Sci., 291, 543-549, 2005
Mochida, M., Kitamori, Y., Kawamura, K., Nojiri, Y., and Suzuki, K.: Fatty acids in the marine atmosphere: factors governing their concentrations and evaluation of organic films on sea-salt particles, J. Geophys. Res., 107, D17S4325, doi:10.1029/2001JD001278, 2002.

Mochida, M., Kawamura, K., Umemoto, N., Kobayashi, M., Matsunaga, S., Lim, H.-J., Turpin, B., Bates, T., and Simoneit, B.: Spatial distributions of oxygenated organic compounds (dicarboxylic acids, fatty acids, and levoglucosan) in marine aerosols over the Western Pacific and off the coast of East Asia: continental outflow of organic aerosols during the ACE-Asia campaign, J. Geophys. Res., 108, D23S8638, doi:10.1029/2002JD003249, 2003.

Murphy, D. M., Cziczo, D. J., Froyd, K. D., Hudson, P. K., Matthew, B. M., Middlebrook, M., Peltier, R. E., Sullivan, A., Thomson, D. S., and Weber, R. J.: Single-particle mass spectrometry of tropospheric aerosol particles, J. Geophys. Res., 111, D23S32, doi:10.1029/2006JD007340, 2006.

O’Dowd, C. D., Facchini, M. C., Cavalli, F., Ceburnis, D., Mircea, M., Decesari, S., Fuzzi, S., Yoon, Y. J., and Putaud, J.-P.: Biogenically driven organic contribution to marine aerosol, Nature, 431, 676-680, 2004.

Oros, D. and Simoneit, B.: Identification and emission rates of molecular tracers in coal smoke particulate matter, Fuel, 79, 515536, 2000

Prisle, N. L., Raatikainen, T., Sorjamaa, R., Svenningsson, B., Laaksonen, A., and Bilde, M.: Surfactant partitioning in cloud droplet activation: a study of C8, C10, C12 and C14 normal fatty acid sodium salts, Tellus B, 60, 416-431, doi:10.1111/j.16000889.2008.00352.x, 2008.

Prisle, N. L., Raatikainen, T., Laaksonen, A., and Bilde, M.: Surfactants in cloud droplet activation: mixed organic-inorganic particles, Atmos. Chem. Phys. Discuss., 9, 24669-24715, doi:10.5194/acpd-9-24669-2009, 2009.

Prisle, N. L., Raatikainen, T., Laaksonen, A. and Bilde, M.: Surfactants in cloud droplet activation: mixed organic-inorganic particles, Atmos. Chem. Phys., 10, 5663-5683, doi:10.5194/acp-105663-2010, 2010.

Raatikainen, T. and Laaksonen, A.: A simplified treatment of surfactant effects on cloud drop activation, Geosci. Model Dev., 4 , 107-116, doi:10.5194/gmd-4-107-2011, 2011.

Seidl, W. and Hanel, G.: Surface-active substances on rainwater and atmospheric particles, Pure Appl. Geophys., 121, 1077-1093, 1983.

Sorjamaa, R., Svenningsson, B., Raatikainen, T., Henning, S., Bilde, M., and Laaksonen, A.: The role of surfactants in Köhler theory reconsidered, Atmos. Chem. Phys., 4, 2107-2117, doi:10.5194/acp-4-2107-2004, 2004.

Szyskowski, B. V.: Experimentelle Studien über kapillare Eigenschaften der wässerigen Lösungen von Fettsäuren, Z. Phys. Chem., 64, 385-414, 1908.

Topping, D.: An analytical solution to calculate bulk mole fractions for any number of components in aerosol droplets after considering partitioning to a surface layer, Geosci. Model Dev., 3, 635642, doi:10.5194/gmd-3-635-2010, 2010.

Tuckermann, R.: Surface tension of aqueous solutions of watersoluble organic and inorganic compounds, Atmos. Environ., 41, 6265-6275, 2007.

Vanhanen, J., Hyvärinen, A.-P., Anttila, T., Raatikainen, T., 
Viisanen, Y., and Lihavainen, H.: Ternary solution of sodium chloride, succinic acid and water; surface tension and its influence on cloud droplet activation, Atmos. Chem. Phys., 8, 45954604, doi:10.5194/acp-8-4595-2008, 2008.

Yassaa, N., Meklati, B. Y., Cecinato, A., and Marino, F.: Particulate n-alkanes, n-alkanoic acids and polycyclic aromatic hydrocarbons in the atmosphere of Algiers City Area, Atmos. Environ., 35, 1843-1851, 2001.
Zhang, Q., Jimenez, J. L., Canagaratna, M. R., Allan, J. D., Coe, H., Ulbrich, I., Alfarra, M. R., Takami, A., Middlebrook, A. M., Sun, Y. L., Dzepina, K., Dunlea, E., Docherty, K., DeCarlo, P. F., Salcedo, D., Onasch, T., Jayne, J. T., Miyoshi, T., Shimono, A., Hatakeyama, S., Takegawa, N., Kondo, Y., Schneider, J., Drewnick, F., Borrmann, S., Weimer, S., Demerjian, K., Williams, P., Bower, K., Bahreini, R., Cottrell, L., Griffin, R. J., Rautiainen, J., Sun, J. Y., Zhang, Y. M., and Worsnop, D. R.: Ubiquity and dominance of oxygenated species in organic aerosols in anthropogenicallyinfluenced Northern Hemisphere midlatitudes, Geophys. Res. Lett., 34,L13801, doi:10.1029/2007GL029979, 2007. 